\title{
Guidelines
}

European

Thyroid Journal
Eur Thyroid J 2018;7:225-237

DOI: 10.1159/000491388
Received: May 28, 2018

Accepted after revision: June 19, 2018

Published online: July 19, 2018

\section{European Thyroid Association (ETA) Guidelines on the Diagnosis and Management of Central Hypothyroidism}

\author{
Luca Persani $^{a, b}$ Georg Brabant ${ }^{c}$ Mehul Dattani ${ }^{d}$ Marco Bonomi ${ }^{a, b}$ \\ Ulla Feldt-Rasmussen ${ }^{\mathrm{e}}$ Eric Fliers ${ }^{f} \quad$ Annette Gruters $^{\mathrm{g}}{ }^{\mathrm{h}}$. Dominique Maiter ${ }^{\mathrm{i}}$ \\ Nadia Schoenmakers ${ }^{j}$ A.S. Paul van Trotsenburgk \\ ${ }^{a}$ Department of Clinical Sciences and Community Health, University of Milan, Milan, Italy; ${ }^{b}$ Division of Endocrine \\ and Metabolic Diseases, IRCCS Istituto Auxologico Italiano, Milan, Italy; ${ }^{C}$ Experimental and Clinical Endocrinology

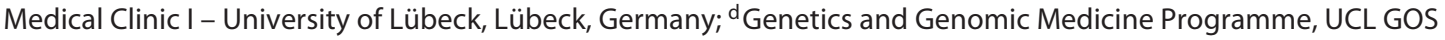 \\ Institute of Child Health, London, UK; ${ }^{~}$ Department of Medical Endocrinology and Metabolism, Rigshospitalet, \\ Copenhagen University Hospital, Copenhagen, Denmark; ${ }^{\mathrm{f}}$ Department of Endocrinology and Metabolism, \\ Academic Medical Center, University of Amsterdam, Amsterdam, The Netherlands; ${ }^{9}$ Department for Pediatric \\ Endocrinology and Diabetes, Charité University Medicine, Berlin, Germany; ${ }^{\text {h}}$ University Hospital Heidelberg, \\ Heidelberg, Germany; 'Department of Endocrinology and Nutrition, UCL Cliniques Saint-Luc, Brussels, Belgium; \\ jUniversity of Cambridge Metabolic Research Laboratories, Wellcome Trust-Medical Research Council Institute \\ of Metabolic Science, Addenbrooke's Hospital and National Institute for Health Research Cambridge Biomedical \\ Research Centre, Addenbrooke's Hospital, Cambridge, UK; ' Department of Pediatric Endocrinology, Emma \\ Children's Hospital, Academic Medical Center, University of Amsterdam, Amsterdam, The Netherlands
}

\section{Keywords}

Central hypothyroidism - Thyroxine - Thyrotropin · TRH · Pituitary · Thyroid · Subclinical hypothyroidism · Guidelines · Hormone replacement therapy

\footnotetext{
Abstract

Objectives: Central hypothyroidism $(\mathrm{CeH})$ is a rare form of hypothyroidism characterized by insufficient thyroid stimulation due to disturbed pituitary and/or hypothalamic functioning. Due to its origin and the whole clinical context, $\mathrm{CeH}$ represents a challenging condition in clinical practice as it is characterized by suboptimal accuracy of clinical and biochemical parameters for diagnosis and management. Since no expert consensus or guidance for this condition is cur-
}

rently available, a task force of experts received the commitment from the European Thyroid Association (ETA) to prepare this document based on the principles of clinical evidence. Study Design: The task force started to work in February 2017 and after a careful selection of appropriate references (cohort studies, case reports, expert opinions), a preliminary presentation and live discussion during the 2017 ETA meeting, and several revision rounds, has prepared a list of recommendations to support the diagnosis and management of patients with $\mathrm{CeH}$. Results: Due to the particular

These ETA guidelines have been endorsed by the European Society of Pediatric Endocrinology (ESPE) and by the European Reference Network for Rare Endocrine Conditions (ENDO-ERN).

\section{KARGER}

E-Mail karger@karger.com www.karger.com/etj (c) 2018 European Thyroid Association

Published by S. Karger AG, Basel
Prof. Luca Persani, MD, PhD

University of Milan and IRCCS Istituto Auxologico Italiano, San Luca Hospital Piazzale Brescia 20 IT-20149 Milan (Italy)

E-Mail luca.persani@unimi.it 
challenges of this rare condition in the different ages, the target users of this guidance are pediatric and adult endocrinologists. Experts agreed on the need to recognize and treat overt $\mathrm{CeH}$ at all ages, whereas treatment of milder forms may be dispensable in the elderly ( $>75$ years). Conclusions: Despite the lack of randomized controlled clinical trials, the experts provide 34 recommendations supported by variable levels of strength that should improve the quality of life of the affected patients and reduce the metabolic and hormonal consequences of inadequate management.

(C) 2018 European Thyroid Association Published by S. Karger AG, Basel

\section{Introduction}

Central hypothyroidism $(\mathrm{CeH})$ is a disorder characterized by defective thyroid hormone production due to insufficient stimulation by thyrotropin (TSH) of an otherwise normal thyroid gland. This condition is the consequence of anatomic or functional disorders of the pituitary gland (secondary hypothyroidism) or the hypothalamus (tertiary hypothyroidism) causing variable alterations of TSH secretion $[1,2]$.

The failure of thyrotrope cells is frequently part of multiple pituitary hormone deficiency (MPHD), a condition complicating both diagnosis and clinical management of $\mathrm{CeH}$. Congenital $\mathrm{CeH}$ can be moderate to severe in approximately half of the cases and consequently affect neurodevelopment [3]. In these cases, a delayed onset of treatment causes irreversible neurological defects. More frequently, diagnosis is made biochemically and should be suspected in every individual with low circulating free thyroxine (FT4) concentrations (free thyroxine index, FTI, can be a valuable alternative if FT4 determination is not available) associated with low or normal serum TSH. Therefore, $\mathrm{CeH}$ represents a major false negative result of the "reflex TSH strategy," which is a widely accepted method for screening thyroid function by a first-line TSH measurement [4-7]. CeH can significantly affect quality of life at all ages. Therefore, the existence of $\mathrm{CeH}$ should always be ruled out in all patients with hypothalamic-pituitary disorders.

\section{Epidemiology}

$\mathrm{CeH}$ most frequently occurs as a sporadic form of hypothyroidism. It can affect patients of all ages and, despite the recent discovery of $\mathrm{X}$-linked forms of $\mathrm{CeH}$, there is no evidence of a sex predominance. The prevalence of $\mathrm{CeH}$ was estimated to range from $1: 16,000$ to about $1: 100,000$ in the general adult or neonatal populations [4, 8-10]. Such variable prevalence probably depends upon several factors, including ethnicity but also differences in sensitivity of the diagnostic strategies.

\section{Pathogenesis}

The mechanisms underlying $\mathrm{CeH}$ pathogenesis variably involve both the hypothalamus and pituitary, but they are still undetermined in several cases. Inheritable conditions are the major cause of $\mathrm{CeH}$ in newborns and infants (Table 1), while gene mutations can also be the underlying cause of $\mathrm{CeH}$ with a delayed onset during childhood or even later in life up to adulthood. Expansive lesions of the hypothalamic/pituitary region constitute the major cause of acquired CeH. However, head trauma, vascular accidents, autoimmunity, hemochromatosis or iron overload, and several iatrogenic mechanisms account for a significant number of $\mathrm{CeH}$ cases. The causes of $\mathrm{CeH}$ are summarized in Table 2.

The pathological mechanisms accounting for $\mathrm{CeH}$ are: (a) impaired thyrotrope stimulation or alterations in the thyroid hormone feedback set point (e.g., TRH resistance or TBL1X mutations) [11-13]; (b) reduced pituitary reserve of thyrotropin (e.g., TSH $\beta$ mutations or an insufficient thyrotrope population); (c) poor intrinsic biological activity of secreted TSH molecules [14-18].

\section{The Path}

Due to its origin and the whole clinical context, $\mathrm{CeH}$ represents a challenging condition in clinical practice. Since no expert consensus or guidance for this condition is currently available, at the end of 2016, the European Thyroid Association (ETA) Executive Committee formed a task force to draft the clinical practice guidelines for the diagnosis and management of $\mathrm{CeH}$. A chairperson was identified (L.P.) and 7 additional members were selected (G.B., U.F.-D., E.F., D.M., N.S., P.T.) and subsequently approved by the ETA Guidelines Board and Executive Committee on the basis of their clinical expertise in the field. Three additional experts (M.B., M.D., A.G.), including two of the European Society of Pediatric Endocrinology (ESPE), were selected to give further inputs to the ETA task force. The members of the task force declare no conflict of interest and worked without any financial support. The draft guid- 
Table 1. Candidate genes in inheritable forms of central hypothyroidism $(\mathrm{CeH})$ and related phenotypes

\begin{tabular}{|c|c|}
\hline Genes $\left(\mathrm{OMIM}^{*}\right)$ & Inheritance and phenotype (OMIM\#) \\
\hline TSH $\beta(188540)$ & $\begin{array}{l}\text { Recessively inherited isolated CeH of neonatal onset with low TSH, high a-GSU and } \\
\text { normal PRL concentrations, pituitary hyperplasia reversible on L-T4 replacement } \\
\text { (275100) }\end{array}$ \\
\hline TRHR (188545) & $\begin{array}{l}\text { Recessively inherited CeH with normal TSH and low PRL concentrations, blunted TSH/ } \\
\text { PRL responses to TRH, male index cases referred for growth retardation or overweight } \\
\text { during childhood, } 1 \text { female proband referred for prolonged neonatal jaundice; no lactation } \\
\text { defect in affected women }\end{array}$ \\
\hline TBL1X (300196) & $\mathrm{X}$-linked mild isolated $\mathrm{CeH}$, normal TSH concentrations, impaired hearing \\
\hline IGSF1 (300137) & $\begin{array}{l}\mathrm{X} \text {-linked CeH (affecting males and females with skewed X chromosome inactivation), } \\
\text { associated with low PRL, variable GH deficiency, metabolic syndrome, and postpubertal } \\
\text { macroorchidism (+2.0 SDS) (300888) }\end{array}$ \\
\hline POU1F1 (173110) & $\begin{array}{l}\text { Dominantly or recessively inherited CeH of variable age of onset, combined with GH and } \\
\text { PRL defects, prominent forehead, midface hypoplasia, depressed nose (613038) }\end{array}$ \\
\hline PROP1 (601538) & $\begin{array}{l}\text { Recessively inherited CeH with variable age of onset, combined with GH, PRL, LH/FSH } \\
\text { defects, and delayed ACTH deficiency, small to large pituitary volume (262600) }\end{array}$ \\
\hline HESX1 (601802) & $\begin{array}{l}\text { Dominantly or recessively inherited hypopituitarism associated with septo-optic dysplasia } \\
(182230)\end{array}$ \\
\hline SOX3 (313430) & $\begin{array}{l}\text { X-linked hypopituitarism, anterior pituitary hypoplasia with ectopic posterior pituitary, } \\
\text { persistent cranio-pharyngeal canal, and learning difficulties ( } 312000)\end{array}$ \\
\hline SOX2 (184429) & $\begin{array}{l}\text { Dominantly inherited variable hypopituitarism, pituitary hypoplasia, microphthalmia, } \\
\text { variable learning difficulties (206990) }\end{array}$ \\
\hline OTX2 & $\begin{array}{l}\text { Dominantly inherited hypopituitarism, anterior pituitary hypoplasia with ectopic } \\
\text { posterior pituitary, and ocular defects (ano/microphthalmia/retinal dystrophy) (610125) }\end{array}$ \\
\hline LHX3 (600577) & $\begin{array}{l}\text { Recessively inherited hypopituitarism with inconstant ACTH defect, small to large } \\
\text { pituitary, short and rigid cervical spine, and variable hearing defect (221750) }\end{array}$ \\
\hline LHX4 (602146) & $\begin{array}{l}\text { Dominant or recessively inherited variable hypopituitarism, anterior pituitary hypoplasia } \\
\text { with ectopic posterior pituitary, Arnold-Chari syndrome, corpus callosum hypoplasia } \\
(262700)\end{array}$ \\
\hline NFKB2 (164012) & $\begin{array}{l}\text { Dominantly inherited DAVID syndrome (variable immune deficiency and ACTH defect) } \\
\text { with variable GH and TSH deficiency (615577) }\end{array}$ \\
\hline CHD7 (608892) & $\begin{array}{l}\text { Dominantly inherited CHARGE syndrome (coloboma, heart anomaly, choanal atresia, } \\
\text { retardation, genital, and ear anomalies) with ectopic posterior pituitary and variable LH/ } \\
\text { FSH, TSH, and GH defects (214800) }\end{array}$ \\
\hline FGFR1 (136350) & $\begin{array}{l}\text { Dominantly inherited Kallmann syndrome (central hypogonadism and anosmia), } \\
\text { variable associations with defects of other pituitary hormones including TSH, } \\
\text { septo-optic dysplasia, and ectopic posterior pituitary }\end{array}$ \\
\hline FGF8 (600483) & $\begin{array}{l}\text { Recessively inherited Kallmann syndrome, variable associations with defects of other } \\
\text { pituitary hormones including TSH, holoprosencephaly, and corpus callosum agenesia }\end{array}$ \\
\hline FOXA2 (600288) & $\begin{array}{l}\text { Dominant hypopituitarism with craniofacial and endoderm-derived organ abnormalities, } \\
\text { and hyperinsulinism }\end{array}$ \\
\hline PROKR2 (607123) & $\begin{array}{l}\text { Variable hypopituitarism associated with septo-optic dysplasia or pituitary stalk } \\
\text { interruption, variable inheritance }\end{array}$ \\
\hline$E P R(601007$ & $\begin{array}{l}\text { Recessively inherited hyperphagia and obesity, combined with central hypogonadi } \\
\text { hypothyroidism (614963) }\end{array}$ \\
\hline
\end{tabular}


Table 2. Causes of $\mathrm{CeH}$

\begin{tabular}{ll}
\hline $\begin{array}{l}\text { Invasive and/or compressive } \\
\text { lesions of the pituitary sella }\end{array}$ & Pituitary macroadenomas \\
region & Craniopharyngiomas \\
& Meningiomas or gliomas \\
& Rathke cleft cysts \\
& Cetastatic seeding \\
\hline Iatrogenic causes & Cranial surgery or irradiation \\
& Drugs (e.g., rexinoids, mitotane) \\
\hline Injuries & Head traumas \\
\hline Vascular accidents & Traumatic delivery \\
\hline Autoimmune diseases & Pituitary infarction \\
& Sheehan syndrome \\
& Subarachnoid hemorrhage \\
\hline Infiltrative lesions & Postpartum hypophysitis \\
& Lymphocytic hypophysitis \\
\hline Inheritable defects & Iron overload \\
\hline Infective diseases & Sarcoidosis \\
& Histiocytosis X \\
\hline & MPHDs or isolated CeH \\
\hline & Tuberculosis \\
& Mycoses \\
\hline
\end{tabular}

ance with the panel's recommendations was released at the end of March 2018 and posted in the "members' only" section of the ETA website for 4 weeks to receive comments.

\section{Evaluation System and Grading for Recommendations}

A systematic literature review of relevant articles was performed by searching PubMed, using the terms "central hypothyroidism," "secondary hypothyroidism," and "tertiary hypothyroidism" up to February 2018. Records from personal files and references of relevant articles and textbooks were also included. The task force critically assessed the literature and identified high-quality studies on $\mathrm{CeH}$. The study designs, the quality and consistency of the results, and the statistical analysis used to assess the effects of $\mathrm{CeH}$ treatment were carefully considered. It was appreciated that only 1 randomized controlled trial (RCT) was available and very few reports fulfilled the established criteria. Retrospective studies and expert opinions were also considered. For this rea- son, this document should be considered as an "expert guidance" for clinical endocrinologists. The task force rated the recommendations according to the GRADE system $[19,20]$. The strength of each statement was classified as strong (1, a recommendation) or weak (2, a suggestion - not a recommendation), depending upon the clinical significance and weight of opinion favoring the statement. Strong recommendations are clinically important best practice and should be applied to most patients in most circumstances. In contrast, weak statements should be considered by the clinician and will be applicable best practice only to certain patients or under certain circumstances. The quality of the literature concerning each aspect of the statement was graded as follows: $\varnothing \bigcirc \bigcirc \bigcirc=$ very low quality (case reports, expert opinion); $\varnothing \varnothing \bigcirc \bigcirc=$ low quality (case series, case reports, expert opinion); $\varnothing \varnothing \varnothing \bigcirc=$ moderate quality (intervention short of RCT or large observational studies), and $\varnothing \varnothing \varnothing \varnothing=$ high quality (RCT evidence/meta-analysis). When appropriate, the level of evidence of some recommendations was upgraded based on studies conducted in primary hypothyroidism. The text and recommendations were then verified according to the AGREE II instrument [21].

\section{Which Patients Are at Risk of CeH?}

The existence of $\mathrm{CeH}$ should be suspected in all subjects with a subnormal circulating concentration of FT4 together with an inappropriately low serum TSH. Importantly, thyroid hormone levels change markedly during childhood and adult reference intervals are not universally applicable to children [22]. Therefore, the establishment of the reference interval of TSH and FT4 is critical in the diagnosis of $\mathrm{CeH}$ as these values can be affected by age, gender, iodine nutrition, and ethnicity [23]. Manifestations of $\mathrm{CeH}$ are similar to those of primary hypothyroidism, but they can be masked by coexistent MPHD [1, 24, 25]. Therefore, $\mathrm{CeH}$ must be suspected and ruled out in all cases with a personal or familial history of hypothalamic-pituitary diseases or with manifestations pointing to a hypothalamic-pituitary lesion. Heritable $\mathrm{CeH}$ should also be ruled out in patients with hypothyroid manifestations associated with particular clinical phenotypes such as macroorchidism, or those with specific neurological manifestations or brain defects on MRI (see Tables 1, 2; Recommendations 1-7; all Recommendations are listed in Appendix 1). 


\section{Heritable $\mathrm{CeH}$}

The number of candidate genes for heritable forms of isolated $\mathrm{CeH}$ or $\mathrm{CPHDs}$ has recently been expanded thanks to next generation sequencing (NGS). The specific manifestations of candidate gene defects are summarized in Table 1.

Heritable forms of $\mathrm{CeH}$ due to biallelic TSH $\beta$ mutations are associated with severe neonatal onset and characterized by the typical manifestations of congenital primary hypothyroidism (e.g., jaundice, macroglossia, hoarse cry, failure to thrive and retarded growth, umbilical hernia, hypotonia). If untreated within a few weeks of postnatal life, these patients develop cretinism comparable to patients with severe primary congenital hypothyroidism $[26,27]$. Therefore, $\mathrm{CeH}$ must be ruled out in all infants with manifestations of congenital hypothyroidism and inappropriately low TSH concentrations.

Defective TRH action due to biallelic mutations in the TRHR gene has, to date, been described in few families $[11,28-30]$. Though prolonged neonatal jaundice was reported in 1 female, even complete TRH resistance does not cause severe neonatal hypothyroidism. The diagnosis in 3 of 4 probands with biallelic TRHR mutations was made during childhood because of delayed growth accompanied by lethargy and fatigue or by overweight. However, complete TRH resistance was uncovered by genetic testing in 1 pregnant woman [11]. Blunted TSH and PRL responses to TRH testing suggest TRHR involvement [11], though normal responses have also been reported when TRHR function is not completely disrupted [30]. Interestingly, heterozygous relatives were reported to have hyperthyrotropinemia in 1 family [30].

Immunoglobulin superfamily member 1 gene (IGSF1) defects are the molecular cause of a recently described Xlinked syndrome including mild to moderate $\mathrm{CeH}$. In this condition, $\mathrm{CeH}$ is associated with abnormal testicular growth leading to adult macroorchidism (+2.0 SDS) but with a tendency towards pubertal delay, low PRL and, rarely, reversible growth hormone $(\mathrm{GH})$ deficiency [12, 31]. Some female carriers can also manifest $\mathrm{CeH}$. Recent data indicate IGSF1 as the most frequently implicated gene in congenital $\mathrm{CeH}$ [32].

Mutations in TBL1X are a second cause of X-linked cause of CeH. TBL1X, transducin-like protein 1, is an essential subunit of the nuclear receptor corepressor (NCoR)-silencing mediator for retinoid and thyroid hormone receptors (SMRT) complex, the major thyroid hormone receptor corepressor involved in T3-regulated gene expression. In addition to $\mathrm{CeH}$, many patients exhibit hearing loss [13].
Table 3. Conditions with biochemical features that could lead to an erroneous $\mathrm{CeH}$ diagnosis

Non-thyroidal illness

Isolated maternal hypothyroxinemia (to be interpreted in the context of trimester-specific FT4 reference ranges for pregnant women)

L-T4 withdrawal syndrome

Recovery from thyrotoxicosis

Technical assay problems or interference, or defects in thyroxine-binding globulin (TBG defects in case of total T4 determination or calculation of FT4 index)

Drugs reducing TSH secretion (glucocorticoids, dopamine, cocaine, anti-epileptics or anti-psychotics, metformin)

Premature birth (delayed TSH rise in hypothyroid infants)

Allan-Herndon-Dudley syndrome (MCT8 mutations)

THRA mutations (RTHa)

TSH $\beta$ mutations with conserved bioactivity but lost immunoreactivity of circulating TSH

Mutations in genes encoding transcription factors that regulate pituitary development are the major cause of heritable MPHDs. In these cases, $\mathrm{CeH}$ can be present at birth but can also have a delayed onset. It is associated with an increased mortality risk in newborns [33] and can be associated with variable manifestations, including hypoglycemia, growth and developmental delay, as well as extra-pituitary abnormalities (e.g., typical craniofacial or brain MRI defects) (Table 1). The recognition of $\mathrm{CeH}$ at neonatal screening and subsequent early diagnosis of congenital MPHD can prevent an impending life-threatening adrenal crisis. The most frequently identified mutations associated with MPHD are in PROP1 [27, 34-37].

\section{Acquired CeH Forms}

In addition to the classic hypothalamic-pituitary diseases (expansive lesions, hypothalamic or pituitary surgery, cranial irradiation, or inflammatory mechanisms), acquired $\mathrm{CeH}$ should be suspected in all patients with moderate to severe head trauma or vascular accident (see Table 2). The possibility of evolution of $\mathrm{CeH}$ should be ruled out in patients with pituitary lesions after the start of replacement therapies with recombinant human growth hormone (rhGH) or estrogen (see [1]) (Recommendation 8) as well as in those receiving particular drugs (Recommendation 9), in particular rexinoids (like bex- 


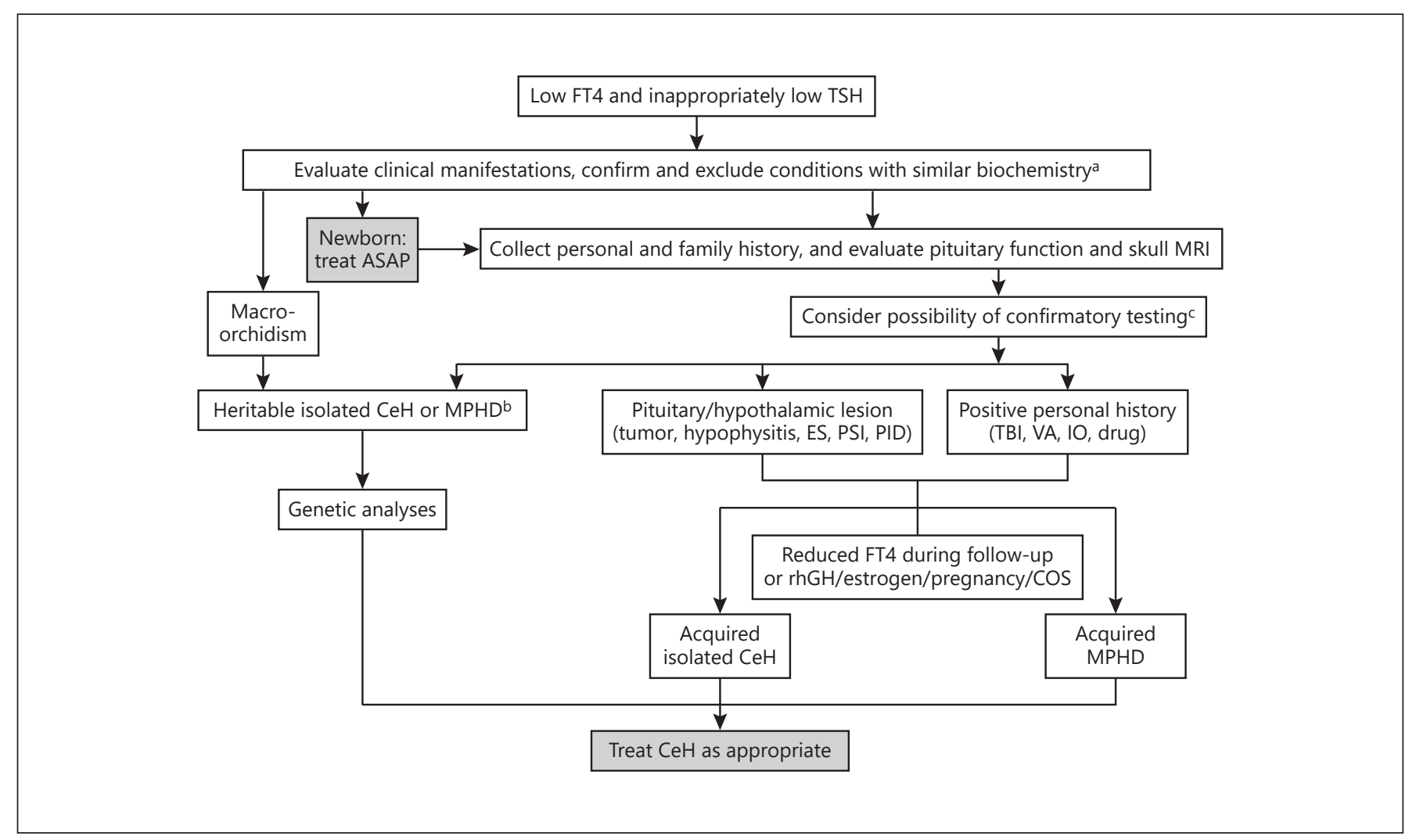

Fig. 1. Flow chart for the diagnosis and management of CeH. MRI, magnetic resonance imaging; $\mathrm{CeH}$, central hypothyroidism; MPHD, multiple pituitary hormone defect; ES, empty sella; PSI, pituitary stalk interruption; PID, pituitary infiltrative disease; TBI, traumatic brain injury; VA, vascular accident; IO, iron overload or

arotene, an agonist of retinoid $\mathrm{X}$ receptor that is approved for clinical use, primarily for treatment of cutaneous Tcell lymphoma) [38] or mitotane (reported to exert toxic effects on thyrotropes) [39]. Several other drugs (e.g., glucocorticoids, anti-epileptics, somatostatin) have transient or controversial TSH-suppressive effects $[1,38]$ (see Table 3). The hypothyroid state is mild to moderate in most patients with acquired $\mathrm{CeH}$, as the pituitary TSH reserve is rarely completely depleted $[40,41]$.

\section{How Can CeH Be Diagnosed?}

The diagnosis of $\mathrm{CeH}$ is generally made biochemically by the combined determination of serum TSH and FT4 (Fig. 1). Overt $\mathrm{CeH}$ is most frequently indicated by the combined findings of low FT4 with low or normal TSH concentrations [24, 25]. Nevertheless, some $\mathrm{CeH}$ patients with a predominant hypothalamic defect can have high hemochromatosis; rhGH, recombinant human growth hormone;

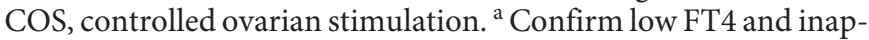
propriately low TSH, and exclude conditions reported in Table 3. ${ }^{b}$ See Table 1 for details. ${ }^{c}$ See Table 4 for details.

serum immunoreactive TSH concentrations, but devoid of full biological activity. In these cases, TSH elevations are similar to those generally found in subclinical or mild primary hypothyroidism and may lead to misdiagnosis $[14-17,30,42]$. The combination of low FT4 and inappropriately low TSH should be confirmed on two separate determinations and after the exclusion of several conditions that could lead to misdiagnosis and are listed in Table 3. In particular, the isolated finding of low FT3 is indicative of nonthyroidal illnesses or deiodinase defects rather than $\mathrm{CeH}$.

In the absence of any technical problem or interference, the finding of low FT4 combined with an inappropriately low or normal TSH accurately delineates the diagnosis of overt forms of $\mathrm{CeH}$, but the diagnosis of milder defects, characterized by FT4 concentrations still within the normal range (mild or hidden $\mathrm{CeH}$ ), remains problematic. Since mild hypothyroidism can be associated with a reduced physical performance and metabolic 
Table 4. Tests and findings useful to support the diagnosis of $\mathrm{CeH}$ in uncertain conditions

Evidence of $\mathrm{CeH}$ in first-degree relatives

Delayed growth, macroorchidism, hearing loss, other signs of hypothyroidism

Causative mutation(s) in $\mathrm{CeH}$ candidate gene(s)

Insufficiency of other pituitary hormone secretion

Blunted ( $<4 \mathrm{mU} / \mathrm{L}$ ) or delayed (peak after $60 \mathrm{~min}$ ) TSH responses to TRH (200 $\mu$ g i.v.)

Blunted nocturnal TSH surge

Low TSH index $(\text { TSHI }=\log \text { TSH }[\mathrm{mU} / \mathrm{L}]+0.1345 \times \mathrm{FT} 4[\mathrm{pM}])^{\mathrm{a}}$

Otherwise unexplained alterations in variables of thyroid hormone action (e.g., high cholesterol, bradycardia, low body temperature, echocardiographic findings)

a TSHI reference interval \pm SD: $2.70 \pm 0.676$ (see [42]).

consequences, as well as with a decreased growth velocity in children, several additional determinations can be useful to support the diagnosis of patients with mild $\mathrm{CeH}$ (borderline low FT4) [1, 43-45] (Table 4). In particular, in patients under follow-up for hypothalamic/pituitary disease, the diagnosis of mild forms of $\mathrm{CeH}$ should be considered when serum FT4 decreases from higher values into the lower quartile of the normal range, in particular when a FT4 decrease $>20 \%$ of previous values is seen despite a low or normal TSH (provided that the indices are measured in the same laboratory and by the same assay) [25]. In such context, an English group proposed the calculation of a TSH index based on the physiological log-linear relationship between circulating FT4 and TSH concentrations in a large reference population [46], and more recently a Brazilian group proposed the determination of echocardiographic parameters [47]. The relative application of the tests and findings reported in Table 4 depends upon the different settings and local regulations (Recommendations 10-14). The determination of the ratio between biological and immunological activity of circulating TSH in experimental biological assays may also be of diagnostic support in certain cases [14-18].

In addition, the task force agreed that a trial of thyroxine treatment over 3 months may be considered to verify its beneficial effects and to support the diagnosis of a mild form of $\mathrm{CeH}$ (borderline low FT4) in patients with otherwise unexplained hypothyroid manifestations.

\section{When and How Should Genetic Analyses Be Performed?}

Genetic analyses should be performed in congenital or familial cases and in cases of $\mathrm{CeH}$ onset during childhood or at any age when the condition remains unexplained (Fig. 1). Genetic testing can also support the diagnosis of idiopathic mild forms of $\mathrm{CeH}$ (borderline low FT4). In index cases, genetic analyses should be performed by direct sequencing following a phenotype-driven approach or by NGS using a panel of candidate genes $[36,48]$ (see Table 1). Importantly, whole exome or genome sequencing (WES or WGS) and/or comparative genomic hybridization (CGH) array can be considered in sporadic or familial cases of $\mathrm{CeH}$ with negative candidate gene analyses. When causative mutations in candidate genes are found, the genetic analyses should be extended to all first-degree relatives for $\mathrm{CeH}$ diagnosis or to uncover the carrier status (Recommendations 15-18).

\section{How Should CeH Patients Be Managed and Treated?}

Whenever a diagnosis of $\mathrm{CeH}$ is confirmed, replacement treatment can be started only after obtaining evidence of conserved cortisol secretion or under proper hydrocortisone replacement. Thus, if coexistent central adrenal insufficiency cannot be ruled out or is not yet treated, thyroid replacement must be started after steroid therapy in order to prevent the possible precipitation of an adrenal crisis, and the assessment of corticotrope function can be postponed (Recommendation 19). However, replacement with thyroid hormone should not be delayed in newborns and infants with symptomatic $\mathrm{CeH}$.

Treatment of $\mathrm{CeH}$ should restore appropriate serum concentrations of thyroid hormones. Since the only trial comparing standard levothyroxine (L-T4) and L-T4 + $\mathrm{L}-\mathrm{T} 3$ combination therapy in $\mathrm{CeH}$ did not prove a superior efficacy of the combination [49], it is recommended that L-T4 monotherapy remains the standard treatment for hypothyroidism (Recommendation 20), in accordance with the American Thyroid Association guidelines [50]. L-T4 + L-T3 combination therapy might be considered as an experimental approach in compliant L-T4treated hypothyroid patients who have persistent complaints despite adequate FT4 concentrations, following the ETA guidance [51]. However, in $\mathrm{CeH}$ where TSH is an unreliable monitor of thyroid hormone status, the risk of overtreatment by this approach is far higher than in primary hypothyroidism [49]. 
In children and young adults, a starting full replacement dose of L-T4 can generally be advised when commencing treatment. In congenital $\mathrm{CeH}$, high L-T4 treatment should be started as soon as possible (optimally within 2 weeks after birth) at doses used also for primary congenital hypothyroidism (10-12 $\mu \mathrm{g} / \mathrm{kg}$ body weight $[\mathrm{bw}] /$ day), in order to rapidly rescue serum FT4 concentrations to normal range and secure optimal neurodevelopment as soon as possible [52]. In milder congenital forms of $\mathrm{CeH}$, commencement of treatment with lower L-T4 doses (5-10 $\mu \mathrm{g} / \mathrm{kg}$ bw/day) can also be considered and should avoid the risk of overtreatment (Recommendations 21, 22).

As in primary hypothyroidism [53], younger $\mathrm{CeH}$ patients require higher doses than the older ones [24, 25]. In children, L-T4 treatment was reported to promote an acceleration of growth velocity allowing attainment of target height $[11,28,43]$. Progressively lower doses are required in the transition to adulthood [54]. Indeed, mean $\mathrm{L}-\mathrm{T} 4$ daily doses of $1.2-1.6 \mu \mathrm{g} / \mathrm{kg} \mathrm{bw} /$ day were judged sufficient in the large majority of adult $\mathrm{CeH}$ patients, with the main aim of achieving a more appropriate metabolic profile $[24,25,55]$. In the elderly or in patients with longstanding hypothyroidism that are at risk of untoward effects mainly due to concomitant heart diseases, L-T4 treatment could be started at a lower daily dosage and then progressively increased during the following weeks or months up to $1.0-1.2 \mu \mathrm{g} / \mathrm{kg}$ bw/day (Recommendations 23, 24). Treatment of milder forms of $\mathrm{CeH}$ (FT4 concentrations within the lower limit of normal range) may be dispensable in elderly patients $>75$ years of age (Recommendation 25).

The determination of circulating free thyroid hormone concentrations is of major significance in monitoring L-T4 treatment in CeH patients [1, 24, 25, 49, 56-58]. Blood should be withdrawn before or at least $4 \mathrm{~h}$ after the L-T4 administration [59]. The determination of FT4 acquires a more relevant role in the evaluation of replacement therapy than in primary hypothyroidism. Several groups $[49,56,58,60]$ reported that concentrations of FT4 in the upper part of normal range might represent an appropriate target in most treated $\mathrm{CeH}$ patients (Recommendation 26).

In primary hypothyroidism, L-T4 replacement is easily tuned by serum TSH measurement, but this parameter has a different significance in $\mathrm{CeH}$ patients. In particular, serum TSH concentrations are rapidly suppressed in a large portion of $\mathrm{CeH}$ patients during the administration of L-T4 [24,25]. A couple of groups also reported that low TSH values are more likely to be associated with adequate replacement in $\mathrm{CeH}$ patients $[61,62]$. Therefore, a TSH value above the lower limit of normal may indicate the need for up-titrating the daily L-T4 dose. However, the TSH determination becomes useless during treatment of $\mathrm{CeH}$ in patients with low baseline concentrations of TSH (Recommendation 27).

Once adequate thyroid replacement is achieved, pediatric patients with $\mathrm{CeH}$ should undergo monitoring of FT4 according to the age-related reference ranges and should be monitored like patients with primary hypothyroidism. An annual monitoring of FT4 should be sufficient in adult $\mathrm{CeH}$ patients. The experts recommend that TSH or T3 should be measured only when insufficient or excessive replacement, respectively, is suspected (Recommendations 28-30).

On the basis of previously illustrated recommendations, an insufficient replacement should be suspected in $\mathrm{CeH}$ patients with serum FT4 concentrations below or close to the lower limit of the normal range, in particular if associated with serum TSH $>1.0 \mathrm{mU} / \mathrm{L}$ and multiple and persistent hypothyroid manifestations (Recommendation 31). Several conditions are associated with increased thyroid hormone requirements through different mechanisms. In comparison with primary hypothyroidism, there is a higher frequency for such conditions because of the persistent impact from rhGH (reviewed in [63]). Estrogen therapy is also known to impact thyroid replacement, and this is even more so when medicallyassisted fertility treatments are used [64], but these effects are generally transient in most patients [25, 65]. During pregnancy, a $25-50 \%$ increase of the L-T4 dose is advised and it is probably better to aim at a higher FT4 concentration, in the upper quartile of the normal range, to minimize the risk of thyroid hormone under-replacement for the fetus [50]. In summary, an up-titration of L-T4 therapy should be considered in all conditions listed in Recommendation 32 .

In contrast, as in the case of primary hypothyroidism, down-titration of the L-T4 dose should be considered in elderly $\mathrm{CeH}$ patients, in particular if associated with cardiovascular morbidities, and after parturition or menopause, or when the concomitant treatments listed in Recommendation 31 are withdrawn (Recommendation 33). The L-T4 overtreatment should be considered in $\mathrm{CeH}$ patients with serum FT4 values above or close to the upper limit of normal (provided that the daily L-T4 dose is taken after blood withdrawal), in particular if associated with clinical thyrotoxic manifestations, or high T3 concentrations (Recommendation 34). 


\section{Disclosure Statement}

All the experts declare no conflict of interest related to the content of the guidance.

\section{Appendix 1: Recommendations}

* Recommendations for pediatric subjects

$\wedge$ Recommendations for adult subjects

Which Patients Are at Risk of $\mathrm{CeH}$ ?

Recommendation $1^{* \wedge}$

We recommend that the diagnosis of $\mathrm{CeH}$ should be considered in every subject with low serum concentrations of FT4 and low or normal TSH on a screening examination.

Strength of recommendation: 1 ; Level of evidence: $\varnothing \varnothing \varnothing \bigcirc$

\section{Recommendation $2^{*}$}

We recommend that the diagnosis of $\mathrm{CeH}$ should be considered in neonates and children with clinical manifestations of congenital hypothyroidism but low or normal neonatal TSH screening.

Strength of recommendation: 1; Level of evidence: $\varnothing \varnothing \varnothing \varnothing$

\section{Recommendation $3^{*} \wedge$}

We suggest that the diagnosis of $\mathrm{CeH}$ should be considered in patients with a low serum concentration of FT4 and slight TSH elevations $(<10 \mathrm{mU} / \mathrm{L}$, or inappropriately lower than expected on the basis of the hypothyroid state).

Strength of recommendation: 2; Level of evidence: $\varnothing \varnothing \bigcirc \bigcirc$

\section{Recommendation $4^{*}$}

We recommend screening for $\mathrm{CeH}$ all children with a familial history of $\mathrm{CeH}$ and/or failure to thrive, developmental delay, $\mathrm{GH}$ deficiency, delayed or precocious puberty, or other hypothalamicpituitary defects or lesions.

Strength of recommendation: 1 ; Level of evidence: $\varnothing \varnothing \varnothing \varnothing$

\section{Recommendation $5^{* \wedge}$}

We recommend that $\mathrm{CeH}$ due to IGSF1 defect should be ruled out in adolescents or adult patients with macroorchidism.

Strength of recommendation: 1 ; Level of evidence: $\varnothing \varnothing \varnothing \bigcirc$

\section{Recommendation $6^{* \wedge}$}

We recommend screening for $\mathrm{CeH}$ all patients with a personal or familial history of hypothalamic-pituitary lesions or diseases, moderate to severe head trauma, stroke, previous cranial irradiation, hemochromatosis or iron overload, in particular when hypothyroid manifestations are present.

Strength of recommendation: 1 ; Level of evidence: $\varnothing \varnothing \varnothing \bigcirc$

\section{Recommendation $7^{* \wedge}$}

We recommend screening for $\mathrm{CeH}$ all patients with hypothyroid manifestations associated with clinical findings pointing to a hypothalamic-pituitary disease (e.g., hyperprolactinemia, acromegalic features, diabetes insipidus, recurrent headaches, visual field defects), newborns with hypotonia and/or prolonged jaundice, and/or signs of congenital hypopituitarism (e.g., micropenis with undescended testes), as well as children with developmental delay.

Strength of recommendation: 1; Level of evidence: $\varnothing \varnothing \varnothing \varnothing$

\section{Recommendation $8^{* \wedge}$}

We recommend that the onset of $\mathrm{CeH}$ should be evaluated in patients with hypothalamic/pituitary disease after the start of treatment with rhGH or estrogen.

Strength of recommendation: 1 ; Level of evidence: $\varnothing \varnothing \varnothing \bigcirc$

\section{Recommendation $9 * \wedge$}

We recommend that the onset of $\mathrm{CeH}$ should be evaluated in patients on treatments with ligands of the retinoid $\mathrm{X}$ receptor (RXR), ipilimumab (or other checkpoint inhibitors), or mitotane.

Strength of recommendation: 1 ; Level of evidence: $\varnothing \varnothing \bigcirc \bigcirc$

How Should CeH Be Diagnosed?

Recommendation $10 * \wedge$

We recommend the combined determination of serum FT4 and TSH in order to evaluate the presence of $\mathrm{CeH}$.

Strength of recommendation: 1 ; Level of evidence: $\varnothing \varnothing \varnothing \varnothing$

\section{Recommendation $11^{* \wedge}$}

We recommend that $\mathrm{CeH}$ diagnosis should be confirmed by the combined findings of serum FT4 concentrations below the lower limit of the normal range and inappropriately low/normal TSH concentrations on at least two separate determinations, and after exclusion of the conditions reported in Table 3.

Strength of recommendation: 1 ; Level of evidence: $\varnothing \varnothing \varnothing \bigcirc$

\section{Recommendation $12 * \wedge$}

The isolated finding of low FT3 or total T3 concentrations is not indicative of $\mathrm{CeH}$, but rather of nonthyroidal illness or deiodination defects (e.g., SBP2 gene defect).

Strength of recommendation: 1 ; Level of evidence: $\varnothing \varnothing \bigcirc \bigcirc$

\section{Recommendation $13 * \wedge$}

In patients under follow-up for hypothalamic-pituitary disease, FT4 and TSH should be monitored during childhood at least biannually and later on a yearly basis, and we suggest that $\mathrm{CeH}$ diagnosis should be considered when serum FT4 falls in the lower quartile of the normal range, in particular when a FT4 decrease $>20 \%$ of previous values is seen (provided that the variables are measured by the same assay) despite a low or normal TSH.

\section{Strength of recommendation: 2; Level of evidence: $\varnothing \bigcirc \bigcirc \bigcirc$}

\section{Recommendation $14^{* \wedge}$}

We suggest that the diagnosis of mild $\mathrm{CeH}$ (borderline low FT4, with inappropriately low TSH) should be supported by a combination of several other findings summarized in Table 4 (the relative application and importance of these tests and findings may vary in different settings).

Strength of recommendation: 2; Level of evidence: $\varnothing \bigcirc \bigcirc$

When and How Should Genetic Analyses Be Performed?

\section{Recommendation $15^{* \wedge}$}

We recommend genetic analyses in congenital cases and in cases of $\mathrm{CeH}$ onset during childhood or at any age when $\mathrm{CeH}$ remains 
unexplained or to support the diagnosis of idiopathic mild forms of $\mathrm{CeH}$ (borderline low FT4).

Strength of recommendation: 1 ; Level of evidence: $\varnothing \varnothing \bigcirc \bigcirc$

\section{Recommendation $16^{* \wedge}$}

In index cases, we recommend genetic analyses by direct sequencing following a phenotype-driven approach or by NGS using a panel of candidate genes (see Table 1).

Strength of recommendation: 1; Level of evidence: $\varnothing \varnothing \bigcirc \bigcirc$

Recommendation $17^{* \wedge}$

We suggest that WES/WGS/CGH array should be considered in sporadic or familial cases of $\mathrm{CeH}$ with negative candidate gene analyses.

Strength of recommendation: 2 ; Level of evidence: $\varnothing \bigcirc \bigcirc$

\section{Recommendation $18^{* \wedge}$}

When causative mutations in candidate genes are found, we recommend the extension of the genetic analyses to all first-degree relatives for (early) $\mathrm{CeH}$ diagnosis or to uncover the carrier status.

Strength of recommendation: 1 ; Level of evidence: $\varnothing \varnothing \varnothing \bigcirc$

How Should CeH Patients Be Managed and Treated?

Recommendation 19*^

We recommend L-T4 as first-line treatment of $\mathrm{CeH}$.

Strength of recommendation: 1 ; Level of evidence: $\varnothing \varnothing \varnothing \varnothing$

\section{Recommendation $20 * \wedge$}

In $\mathrm{CeH}$ patients, we recommend starting replacement treatment with L-T4 only after evidence of conserved cortisol secretion. If coexistent central adrenal insufficiency is not ruled out, thyroid replacement must be started after steroid therapy in order to prevent the possible induction of an adrenal crisis.

Strength of recommendation: 1 ; Level of evidence: $\varnothing \varnothing \varnothing \varnothing$

\section{Recommendation 21*}

In congenital and severe forms of $\mathrm{CeH}$ (e.g., TSH $\beta$ mutations), we recommend starting L-T4 treatment as soon as possible (optimally within 2 weeks after birth) at doses used also for primary congenital hypothyroidism (10-12 $\mu \mathrm{g} / \mathrm{kg}$ bw/day), in order to rapidly rescue serum FT4 levels to normal range and secure optimal treatment as quickly as possible.

Strength of recommendation: 1 ; Level of evidence: $\varnothing \varnothing \varnothing \varnothing$

\section{Recommendation $22^{*}$}

In milder forms of congenital $\mathrm{CeH}$, we suggest to start replacement therapy at lower L-T4 doses $(5-10 \mu \mathrm{g} / \mathrm{kg}$ bw/day), to avoid the risk of overtreatment.

Strength of recommendation: 2; Level of evidence: $\varnothing \bigcirc \bigcirc \bigcirc$

Recommendation 23*

In $\mathrm{CeH}$ forms diagnosed during childhood or adolescence, we recommend to start L-T4 treatment at doses of 3.0-5.0 or 2.0-2.4 $\mu \mathrm{g} / \mathrm{kg}$ bw/day, respectively.

Strength of recommendation: 1 ; Level of evidence: $\varnothing \varnothing \bigcirc \bigcirc$

\section{Recommendation $24^{\wedge}$}

In adult patients with $\mathrm{CeH}$, we recommend targeting of $\mathrm{L}-\mathrm{T} 4$ replacement to a dose according to age and bw:
- $1.21-1.6 \mu \mathrm{g} / \mathrm{kg}$ bw/day in patients younger than 60 years of age

- $1.0-1.2 \mu \mathrm{g} / \mathrm{kg}$ bw/day in adults older than 60 years of age, or in younger patients with concomitant cardiac disease Strength of recommendation: 1 ; Level of evidence: $\varnothing \varnothing \bigcirc \bigcirc$

\section{Recommendation $25^{\wedge}$}

As in primary disease, we recommend to avoid treatment of milder forms of $\mathrm{CeH}$ (FT4 concentrations within the lower limit of normal range) in elderly patients $>75$ years of age.

Strength of recommendation: 1 ; Level of evidence: $\varnothing \varnothing \bigcirc \bigcirc$

\section{Recommendation $26^{* \wedge}$}

In patients with $\mathrm{CeH}$, we recommend to check adequacy of replacement therapy 6-8 weeks after the start of L-T4 replacement with concomitant FT4 and TSH measurements, provided that blood is withdrawn before the morning replacement dose or at least $4 \mathrm{~h}$ after the L-T4 administration. We recommend that replacement therapy should be aimed to maintain FT4 above the median value of the normal range.

Strength of recommendation: 1 ; Level of evidence: $\varnothing \varnothing \varnothing \bigcirc$

\section{Recommendation $27 * \wedge$}

Low TSH concentrations in serum point to an adequate replacement in $\mathrm{CeH}$ patients with TSH values above the lower limit of normal range at baseline. The TSH determination becomes useless during treatment of $\mathrm{CeH}$ cases with low TSH values at baseline.

Strength of recommendation: 1 ; Level of evidence: $\varnothing \varnothing \bigcirc \bigcirc$

\section{Recommendation 28*}

Once adequate thyroid replacement is achieved, we recommend monitoring pediatric patients with $\mathrm{CeH}$ by maintaining FT4 concentrations according to the age-related reference ranges and their follow-up should be conducted like in patients with primary hypothyroidism.

Strength of recommendation: 1 ; Level of evidence: $\varnothing \varnothing \varnothing \bigcirc$

\section{Recommendation $29 \wedge$}

Once adequate thyroid replacement is achieved, we recommend annual monitoring of FT4 in adult patients with $\mathrm{CeH}$.

Strength of recommendation: 1 ; Level of evidence: $\varnothing \varnothing \varnothing \bigcirc$

Recommendation $30 * \wedge$

We recommend that TSH and/or T3 (total or free) should be measured in $\mathrm{CeH}$ patients when insufficient or excessive replacement is suspected.

Strength of recommendation: 1 ; Level of evidence: $\varnothing \varnothing \bigcirc \bigcirc$

\section{Recommendation $31^{* \wedge}$}

We recommend that insufficient thyroid replacement should be considered in $\mathrm{CeH}$ patients when serum FT4 concentrations are below or close to the lower limit of the normal range, in particular if associated with serum TSH $>1.0 \mathrm{mU} / \mathrm{L}$ and multiple and persistent hypothyroid manifestations.

\section{Strength of recommendation: 1 ; Level of evidence: $\varnothing \varnothing \bigcirc \bigcirc$}

Recommendation $32 * \wedge$

In $\mathrm{CeH}$ patients, we recommend to consider up-titration of the $\mathrm{L}-\mathrm{T} 4$ dose in all conditions listed below:

- retarded psychomotor and cognitive development in infants and children; 
- introduction of GH replacement therapy;

- introduction of estrogen replacement therapy or oral contraceptives;

- pubertal development;

- controlled ovarian stimulation;

- pregnancy;

- weight gain;

- introduction of treatments impacting L-T4 absorption or thyroid hormone metabolism.

In these cases, TSH and FT4 should be measured 4-6 weeks after the up-titration in order to check the adequacy of replacement.

Strength of recommendation: 1 ; Level of evidence: $\varnothing \varnothing \bigcirc \bigcirc$

\section{Recommendation $33^{\wedge}$}

We recommend down-titration of the L-T4 dose in elderly $\mathrm{CeH}$ patients, in particular with associated cardiovascular morbidities, and after parturition or menopause or weight loss, or when the concomitant treatments listed in Recommendation 31 are withdrawn.

In these cases, TSH and FT4 should be measured 4-6 weeks after the down-titration in order to check the adequacy of replacement.

Strength of recommendation: 1 ; Level of evidence: $\varnothing \varnothing \bigcirc \bigcirc$

\section{Recommendation $34 * \wedge$}

We recommend that $\mathrm{L}-\mathrm{T} 4$ overtreatment should be considered in $\mathrm{CeH}$ patients when serum FT4 concentrations are above or close to the upper limit of normal (provided that L-T4 is taken after blood withdrawal), in particular if associated with clinical thyrotoxic manifestations, or high T3 concentrations.

Strength of recommendation: 1 ; Level of evidence: $\varnothing \varnothing \bigcirc \bigcirc$

\section{References}

1 Persani L: Clinical review: central hypothyroidism: pathogenic, diagnostic, and therapeutic challenges. J Clin Endocrinol Metab 2012;97:3068-3078.

2 Persani L, Beck-Peccoz P: Central hypothyroidism; in Braverman LE, Cooper D (ed): Werner and Ingbar's The Thyroid: A Fundamental and Clinical Text, ed 10. Lippincott Williams and Wilkins/Wolters Kluwer Health, Philadelphia, 2012, pp 560-568.

3 Zwaveling-Soonawala N, van Trotsenburg AS, Verkerk PH: The severity of congenital hypothyroidism of central origin should not be underestimated. J Clin Endocrinol Metab 2015;100:E297-E300.

4 Price A, Weetman AP: Screening for central hypothyroidism is unjustified. Br Med J 2001; 322:798.

5 Baloch Z, Carayon P, Conte-Devolx B, Demers LM, Feldt-Rasmussen U, Henry JF, LiVosli VA, Niccoli-Sire P, John R, Ruf J, Smyth PP, Spencer CA, Stockigt JR: Laboratory medicine practice guidelines. Laboratory support for the diagnosis and monitoring of thyroid disease. Thyroid 2003;13:3-126.

6 Wardle CA, Fraser WD, Squire CR: Pitfalls in the use of thyrotropin concentration as a firstline thyroid-function test. Lancet 2001;357: 1013-1014.

7 Baquedano MS, Ciaccio M, Dujovne N, Herzovich V, Longueira Y, Warman DM, Rivarola MA, Belgorosky A: Two novel mutations of the TSH-beta subunit gene underlying congenital central hypothyroidism undetectable in neonatal TSH screening. J Clin Endocrinol Metab 2010;95:E98-E103.

8 Kempers MJ, van der Sluijs Veer L, Nijhuisvan der Sanden RW, Lanting CI, Kooistra L, Wiedijk BM, Last BF, de Vijlder JJ, Grootenhuis MA, Vulsma T: Neonatal screening for congenital hypothyroidism in the Netherlands: cognitive and motor outcome at 10 years of age. J Clin Endocrinol Metab 2007;92: 919-924.
9 Nebesio TD, McKenna MP, Nabhan ZM, Eugster EA: Newborn screening results in children with central hypothyroidism. J Pediatr 2010;156:990-993.

10 Adachi M, Soneda A, Asakura Y, Muroya K, Yamagami Y, Hirahara F: Mass screening of newborns for congenital hypothyroidism of central origin by free thyroxine measurement of blood samples on filter paper. Eur J Endocrinol 2012;166:829-838.

11 Bonomi M, Busnelli M, Beck-Peccoz P, Costanzo D, Antonica F, Dolci C, Pilotta A, Buzi F, Persani L: A family with complete resistance to thyrotropin-releasing hormone. N Engl J Med 2009;360:731-734.

12 Sun Y, Bak B, Schoenmakers N, van Trotsenburg AS, Oostdijk W, Voshol P, Cambridge E, White JK, le Tissier P, Gharavy SN, MartinezBarbera JP, Stokvis-Brantsma WH, Vulsma T, Kempers MJ, Persani L, Campi I, Bonomi M, Beck-Peccoz P, Zhu H, Davis TM, HokkenKoelega AC, Del Blanco DG, Rangasami JJ, Ruivenkamp CA, Laros JF, Kriek M, Kant SG, Bosch CA, Biermasz NR, Appelman-Dijkstra NM, Corssmit EP, Hovens GC, Pereira AM, den Dunnen JT, Wade MG, Breuning MH, Hennekam RC, Chatterjee K, Dattani MT, Wit JM, Bernard DJ: Loss-of-function mutations in IGSF1 cause an X-linked syndrome of central hypothyroidism and testicular enlargement. Nat Genet 2012;44:1375-1381.

13 Heinen CA, Losekoot M, Sun Y, Watson PJ, Fairall L, Joustra SD, Zwaveling-Soonawala N, Oostdijk W, van den Akker EL, Alders M, Santen GW, van Rijn RR, Dreschler WA, Surovtseva OV, Biermasz NR, Hennekam RC, Wit JM, Schwabe JW, Boelen A, Fliers E, van Trotsenburg AS: Mutations in TBL1X are associated with central hypothyroidism. J Clin Endocrinol Metab 2016;101:4564-4573.

14 Faglia G, Bitensky L, Pinchera A, Ferrari C, Paracchi A, Beck-Peccoz P, Ambrosi B, Spada $A$ : Thyrotropin secretion in patients with central hypothyroidism: evidence for reduced bio- logical activity of immunoreactive thyrotropin. J Clin Endocrinol Metab 1979;48:989-998.

15 Beck-Peccoz P, Amr S, Menezes-Ferreira MM, Faglia G, Weintraub BD: Decreased receptor binding of biologically inactive thyrotropin in central hypothyroidism. Effect of treatment with thyrotropin-releasing hormone. N Engl J Med 1985;312:1085-1090.

16 Horimoto M, Nishikawa M, Ishihara T, Yoshikawa N, Yoshimura M, Inada M: Bioactivity of thyrotropin (TSH) in patients with central hypothyroidism: comparison between in vivo 3,5,3'-triiodothyronine response to TSH and in vitro bioactivity of TSH. J Clin Endocrinol Metab 1995;80:1124-1128.

17 Persani L, Ferretti E, Borgato S, Faglia G, Beck-Peccoz P: Circulating thyrotropin bioactivity in sporadic central hypothyroidism. J Clin Endocrinol Metab 2000;85:3631-3635.

18 Persani L, Tonacchera M, Beck-Peccoz P, Vitti P, Mammoli C, Chiovato L, Elisei R, Faglia G, Ludgate M, Vassart G: Measurement of cAMP accumulation in Chinese hamster ovary cells transfected with the recombinant human TSH receptor (CHO-R): a new bioassay for human thyrotropin. J Endocrinol Invest 1993;16:511-519.

19 Guyatt GH, Oxman AD, Vist GE, et al; GRADE Working Group: GRADE: an emerging consensus on rating quality of evidence and strength of recommendations. Br Med J 2008;336:924-926.

20 Swiglo BA, Murad MH, Schunemann HJ, Kunz R, Vigersky RA, Guyatt GH, Montori VM: A case for clarity, consistency, and helpfulness: state-of-the-art clinical practice guidelines in endocrinology using the grading of recommendations, assessment, development, and evaluation system. J Clin Endocrinol Metab 2008;93:666-673.

21 Brouwers MC, Kho ME, Browman GP, et al: AGREE II: Advancing guideline development, reporting and evaluation in healthcare. CMAJ 2010;182:E839-E842. 
22 Kapelari K, Kirchlechner C, Högler W, Schweitzer K, Virgolini I, Moncayo R: Pediatric reference intervals for thyroid hormone levels from birth to adulthood: a retrospective study. BMC Endocr Disord 2008;8:15.

23 Park SY, Kim HI, Oh HK, Kim TH, Jang HW, Chung JH, Shin MH, Kim SW: Age- and gender-specific reference intervals of TSH and free T4 in an iodine-replete area: data from Korean National Health and Nutrition Examination Survey IV (2013-2015). PLoS One 2018;13:e0190738.

24 Ferretti E, Persani L, Jaffrain-Rea ML, Giambona S, Tamburrano G, Beck-Peccoz P: Evaluation of the adequacy of levothyroxine replacement therapy in patients with central hypothyroidism. J Clin Endocrinol Metab 1999;84:924-929.

25 Alexopoulou O, Beguin C, De Nayer P, Maiter D: Clinical and hormonal characteristics of central hypothyroidism at diagnosis and during follow-up in adult patients. Eur J Endocrinol 2004;150:1-8.

26 Bonomi M, Proverbio MC, Weber G, Chiumello G, Beck-Peccoz P, Persani L: Hyperplastic pituitary gland, high serum glycoprotein hormone alpha-subunit, and variable circulating thyrotropin (TSH) levels as hallmark of central hypothyroidism due to mutations of the TSH beta gene. J Clin Endocrinol Metab 2001; 86:1600-1604.

27 Miyai K: Congenital thyrotropin deficiency from discovery to molecular biology, postgenome and preventive medicine. Endocr 2007;54:191-203.

28 Collu R, Tang J, Castagne J, Lagace G, Masson N, Huot C, Deal C, Delvin E, Faccenda E, Eidne KA, Van Vliet G: A novel mechanism for isolated central hypothyroidism: inactivating mutations in the thyrotropin-releasing hormone receptor gene. J Clin Endocrinol Metab 1997;82:1561-1565.

29 Koulouri O, Nicholas AK, Schoenmakers E, Mokrosinski J, Lane F, Cole T, Kirk J, Farooqi IS, Chatterjee VK, Gurnell M, Schoenmakers $\mathrm{N}$ : A novel thyrotropin-releasing hormone receptor missense mutation (P81R) in central congenital hypothyroidism. J Clin Endocrinol Metab 2016;101:847-851.

30 Garcia M, Gonzalez de Buitrago J, JimenezRoses M, Pardo L, Hinkle PM, Moreno JC: Central hypothyroidism due to a TRHR mutation causing impaired ligand affinity and transactivation of Gq. J Clin Endocrinol Metab 2017;102:2433-2442.

31 Joustra SD, van der Plas EM, Goede J, Oostdijk W, Delemarre-van de Waal HA, Hack WW, van Buuren S, Wit JM: New reference charts for testicular volume in Dutch children and adolescents allow the calculation of standard deviation scores. Acta Paediatr 2015; 104:e271-e278
32 Joustra SD, Heinen CA, Schoenmakers N, Bonomi M, Ballieux BE, Turgeon MO, Bernard DJ, Fliers E, van Trotsenburg AS, Losekoot M, Persani L, Wit JM, Biermasz NR, Pereira AM, Oostdijk W: IGSF1 deficiency: lessons from an extensive case series and recommendations for clinical management. J Clin Endocrinol Metab 2016;101:1627-1636.

33 Zwaveling-Soonawala N, Naafs JC, Verkerk $\mathrm{PH}$, van Trotsenburg ASP: Mortality in children with early detected congenital central hypothyroidism. J Clin Endocrinol Metab 2018, Epub ahead of print.

34 Yamada M, Mori M: Mechanisms related to the pathophysiology and management of central hypothyroidism. Nat Clin Pract Endocrinol Metab 2008;4:683-694.

35 Pfaffle R, Klammt J: Pituitary transcription factors in the aetiology of combined pituitary hormone deficiency. Best Pract Res Clin Endocrinol Metab 2011;25:43-60.

36 Persani L, Bonomi M: The multiple genetic causes of central hypothyroidism. Best Pract Res Clin Endocrinol Metab 2017;31:255-263.

37 Giri D, Vignola ML, Gualtieri A, Scagliotti V, McNamara P, Peak M, Didi M, Gaston-Massuet C, Senniappan S: Novel FOXA2 mutation causes hyperinsulinism, hypopituitarism with craniofacial and endoderm-derived organ abnormalities. Hum Mol Genet 2017;26: 4315-4326.

38 Haugen BR: Drugs that suppress TSH or cause central hypothyroidism. Best Pract Res Clin Endocrinol Metab 2009;23:793-800.

39 Russo M, Scollo C, Pellegriti G, Cotta OR, Squatrito S, Frasca F, Cannavò S, Gullo D: Mitotane treatment in patients with adrenocortical cancer causes central hypothyroidism. Clin Endocrinol (Oxf) 2016;84:614-6199.

40 Neumann S, Raaka BM, Gershengorn MC: Constitutively active thyrotropin and thyrotropin-releasing hormone receptors and their inverse agonists. Methods Enzymol 2010;485: 147-160.

41 Barbesino G, Sluss PM, Caturegli P: Central hypothyroidism in a patient with pituitary autoimmunity: evidence for TSH-independent thyroid hormone synthesis. J Clin Endocrinol Metab 2012;97:345-350.

42 Lee KO, Persani L, Tan M, Sundram FX, Beck-Peccoz P: Thyrotropin with decreased biological activity, a delayed consequence of cranial irradiation for nasopharyngeal carcinoma. J Endocrinol Invest 1995;18:800-805.

43 Rose SR: Cranial irradiation and central hypothyroidism. Trends Endocrinol Metab 2001;12:97-104.

44 Rose SR, Lustig RH, Pitukcheewanont P, Broome DC, Burghen GA, Li H, Hudson MM, Kun LE, Heideman RL: Diagnosis of hidden central hypothyroidism in survivors of childhood cancer. J Clin Endocrinol Metab 1999;84:4472-4479.

45 Darzy KH, Shalet SM: Circadian and stimulated thyrotropin secretion in cranially irradiated adult cancer survivors. J Clin Endocrinol Metab 2005;90:6490-6497.
46 Jostel A, Ryder WD, Shalet SM: The use of thyroid function tests in the diagnosis of hypopituitarism: definition and evaluation of the TSH Index. Clin Endocrinol (Oxf) 2009; 71:529-534.

47 Doin FC, Rosa-Borges M, Martins MR, Moisés VA, Abucham J: Diagnosis of subclinical central hypothyroidism in patients with hypothalamic-pituitary disease by Doppler echocardiography. Eur J Endocrinol 2012; 166:631-640

48 Persani L, de Filippis T, Colombo C, Gentilini D: Genetics in endocrinology: genetic diagnosis of endocrine diseases by NGS: novel scenarios and unpredictable risks. Eur J Endocrinol 2018, Epub ahead of print.

49 Slawik M, Klawitter B, Meiser E, Schories M, Zwermann O, Borm K, Peper M, Lubrich B, Hug MJ, Nauck M, Olschewski M, Beuschlein F, Reincke M: Thyroid hormone replacement for central hypothyroidism: a randomized controlled trial comparing two doses of thyroxine (T4) with a combination of T4 and triiodothyronine. J Clin Endocrinol Metab 2007;92:4115-4122.

50 Jonklaas J, Bianco AC, Bauer AJ, Burman KD, Cappola, AR, Celi FS, Cooper DS, Kim BW, Peeters RP, Rosenthal MS, Sawka AM: Guidelines for the treatment of hypothyroidism. Thyroid 2014;24:1670-1751.

51 Wiersinga WM, Duntas L, Fadeyev V, Nygaard B, Vanderpump MP: 2012 ETA guidelines: the use of L-T4 + L-T3 in the treatment of hypothyroidism. Eur Thyroid J 2012; 1:55-71.

52 Aleksander P, Bruckner-Spieler M, Stohr AM, Lankes E, Kuhnen P, Schnabel D, Ernert A, Stablein W, Craig ME, Blankenstein $\mathrm{O}$, Gruters A, Krude H: Mean high dose L-thyroxine treatment is efficient and safe to achieve a normal IQ in young adult patients with congenital hypothyroidism. J Clin Endocrinol Metab 2018;103:1459-1469.

53 Helfand M, Crapo LM: Monitoring therapy in patients taking levothyroxine. Ann Int Med 1990;113:450-454.

54 Koch CA, Sarlis NJ: The spectrum of thyroid diseases in childhood and its evolution during transition to adulthood: natural history, diagnosis, differential diagnosis and management. J Endocrinol Invest 2001;24:659-675.

55 Feldt-Rasmussen U, Klose M: Central hypothyroidism and its role for cardiovascular risk factors in hypopituitary patients. Endocrine 2016;54:15-23.

56 Iverson JF, Mariash CN: Optimal free thyroxine levels for thyroid hormone replacement in hypothyroidism. Endocr Pract 2008;14:550555

57 Beck-Peccoz P: Treatment of central hypothyroidism. Clin Endocrinol 2011;74:671672. 
58 Koulouri O, Auldin MA, Agarwal R, Kieffer V, Robertson C, Falconer Smith J, Levy MJ, Howlett TA: Diagnosis and treatment of hypothyroidism in TSH deficiency compared to primary thyroid disease: pituitary patients are at risk of under-replacement with levothyroxine. Clin Endocrinol 2011;74:744-749.

59 Leger J, Olivieri A, Donaldson M, Torresani T, Krude H, van Vliet G, Polak M, Butler G: European Society for Paediatric Endocrinology consensus guidelines on screening, diagnosis, and management of congenital hypothyroidism. Horm Res Paediatr 2014;81:80103.
60 Hirata Y, Fukuoka H, Iguchi G, Iwahashi Y, Fujita Y, Hari Y, Iga M, Nakajima S, Nishimoto Y, Mukai M, Hirota Y, Sakaguchi K, Ogawa W, Takahashi Y: Median-lower normal levels of serum thyroxine are associated with low triiodothyronine levels and body temperature in patients with central hypothyroidism. Eur J Endocrinol 2015;173:247-256.

61 Carrozza V, Csako G, Yanovski JA, Skarulis MC, Nieman L, Wesley R, Pucino F: Levothyroxine replacement therapy in central hypothyroidism: a practice report. Pharmacotherapy 1999;19:349-355.

62 Shimon I, Cohen O, Lubetsky A, Olchovsky D: Thyrotropin suppression by thyroid hormone replacement is correlated with thyroxine level normalization in central hypothyroidism. Thyroid 2002;12:823-827.
63 Beck-Peccoz P, Rodari G, Giavoli C, Lania A: Central hypothyroidism - a neglected thyroid disorder. Nat Rev Endocrinol 2017;13:588598.

64 Benaglia L, Busnelli A, Somigliana E, Leonardi M, Vannucchi G, De Leo S, Fugazzola L, Ragni G, Fedele L: Incidence of elevation of serum thyroid-stimulating hormone during controlled ovarian hyperstimulation for in vitro fertilization. Eur J Obstet Gynecol Reprod Biol 2014;173:53-57.

65 Arafah BM: Increased need for thyroxine in women with hypothyroidism during estrogen therapy. N Engl J Med 2001;344:1743-1749. 